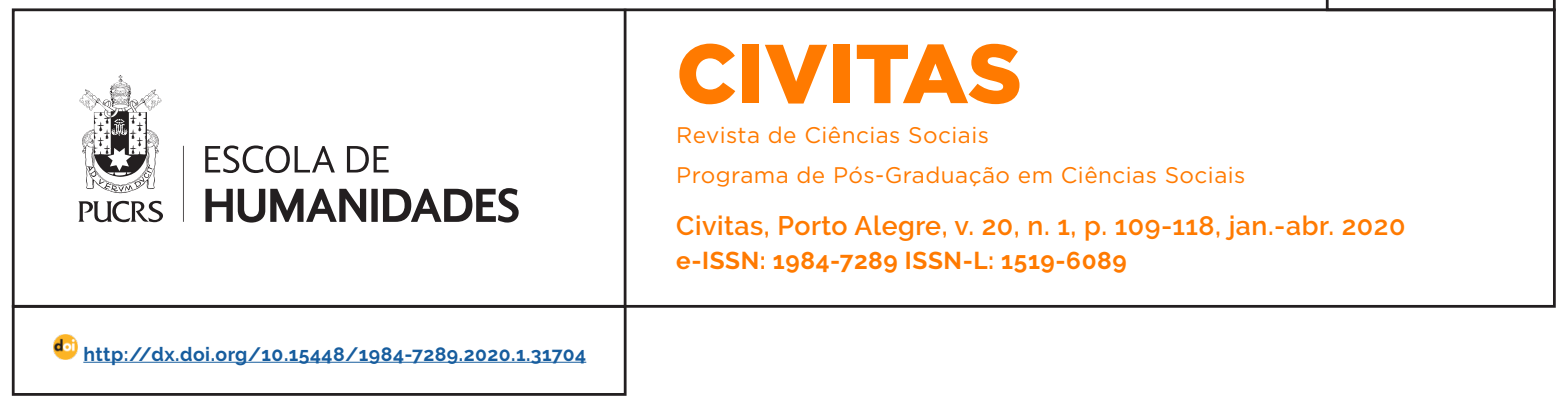

ARTIGOS/ARTICLES

\title{
As tramas da participação na pedagogia freireana: fundamentos para uma democracia radical
}

\author{
The weft of participation in freirean pedagogy: foundations for a radical democracy \\ Las tramas de la pedagogía freireana en la participación: fundamentos para una \\ democracia radical
}

\section{Sandro de Castro \\ Pitano $^{1}$}

orcid.org/0000-0002-9794-1303

scpitano@gmail.com

\section{Danilo Romeu Streck \\ orcid.org/0000-0001-7410-3174 \\ streckdr@gmail.com}

\section{Cheron Zanini Moretti ${ }^{3}$}

orcid.org/0000-0002-6297-3129

cheron.moretti@gmail.com

Recebido em: 16 ago. 2018

Aprovado em: 6 nov. 2019

Publicado em: 25 mai. 2020
Resumo: Nesse artigo busca-se compreender os princípios da participação na forma de uma trama complexa, a partir do pensamento político e pedagógico de Paulo Freire. Indaga-se, entre outras questões, sobre as experiências históricas, direta ou indiretamente vivenciadas, que o influenciaram na incorporação da participação como premissa basilar de sua pedagogia. No campo das influências teóricas analisa-se a presença de autores/as identificados/as em sua obra, compreendendo as apropriações que Paulo Freire efetua e como as articula no dimensionamento da participação como democracia radical. As tramas da participação na pedagogia freireana fundamentam uma concepção de democracia que se manifesta como protagonismo histórico, como ação relacional-humanizadora e como prática de liberdade.

Palavras-chave: Paulo Freire. Participação. Democracia radical. Pedagogia.

Abstract: This article seeks to understand the principles of participation in the form of a complex weft, based on Paulo Freire's political and pedagogical thinking. Among other issues, the text reflects on the historical experiences, directly or indirectly experienced in Freire's life that influenced the incorporation of participation as a basic premise of his pedagogy. In the field of theoretical influences the presence of authors identified in his work are analyzed in terms of their appropriation by Paulo Freire and the way he articulates them in the dimension of participation as a radical democracy. The weft of participation in Freirean pedagogy is the basis for a conception of democracy that manifests itself as historical protagonism, as relational-humanizing action and as a practice of freedom.

Keywords: Paulo Freire. Participation. Radical democracy. Pedagogia.

Resumen: En este artículo se busca comprender los principios de la participación en la forma de una trama compleja, a partir del pensamiento político y pedagógico de Paulo Freire. Se indaga, entre otras cuestiones, sobre las experiencias históricas, directa o indirectamente vivenciadas, que lo influenciaron en la incorporación de la participación como premisa principal de su pedagogía. En el campo de las influencias teóricas se analiza la presencia de autores/as identificadas en su obra, comprendiendo las apropiaciones que Paulo Freire efectúa y cómo las articula en el dimensionamiento de la participación como democracia radical. Las tramas de la participación en la pedagogía freireana fundamentan una concepción de democracia que se manifiesta como protagonismo histórico, como acción relacional-humanizadora y como práctica de libertad.

Palabras clave: Paulo Freire. Participación. Democracia Radical. Pedagogía. 


\section{Introdução}

Este artigo se origina de um projeto recentemente concluido: "As articulações teóricas e metodológicas do pensamento de Paulo Freire: diálogos explícitos, implícitos e possiveis". Trata-se de uma investigação que desenvolveu um amplo estudo sobre o conjunto da obra de Paulo Freire, buscando identificar os autores e correntes de pensamento nela presentes, compreendendo de que formas foram incorporados ao longo da sua sistematização, consolidando um conjunto de raizes intelectuais. Além de identificar autores e correntes que contribuem na sistematização do pensamento freireano, buscou-se compreender de que modo são articulados; quais conceitos e concepções desses autores são apropriados por Freire e como ele os relaciona no conjunto de sua obra. Para tanto, organizamos 32 livros publicados em português, em cinco periodos: 1) até 1964, antes do Golpe Civil Militar; 2) até 1980, no periodo de exilio; 3) pós-1980, retorno do exilio-obras dialogadas; 4) escritos pós experiência de gestão na Secretaria Municipal de Educação, em São Paulo (SME-SP); e. 5) obras organizadas, póstumas. Realizamos a leitura e o fichamento de cada um deles considerando os aspectos já mencionados. Denominamos esse trabalho como "arqueologia bibliográfica" de Paulo Freire, ou simplesmente de "trama".

Neste artigo buscamos compreender em profundidade, embora sem a pretensão de esgotar o tema, os princípios da participação que permeiam, na forma de uma trama complexa, o pensamento político e pedagógico de Paulo Freire. Indaga-se, entre outras questões, sobre as experiências históricas, direta ou indiretamente vivenciadas, que o teriam influenciado na incorporação da participação como premissa basilar de sua pedagogia libertadora. Além disso, buscamos analisar e compreender as apropriações que ele efetua e suas articulações no dimensionamento dessa participação com algumas dessas influências. Assim, merecem destaque os seguintes temas e respectivos autores: o movimento da consciência e seus niveis
- Álvaro Vieira Pinto; o diálogo como fundamento - Martin Buber, Karl Jaspers e Gabriel Marcel e o conhecimento dialógico, de Eduardo Nicol; historicidade, formação histórico-social do sujeito e protagonismo - Karl Marx, Lev Semionovich Vigotski e Erich Fromm; responsabilidade política e compromisso com a democratização social Franz Fanon, Zevedei Barbu e Karl Mannheim; e a análise sociológica de Wright Mills. ${ }^{4}$

Na primeira parte do texto desenvolvemos uma breve abordagem conceitual sobre a participação e seu vínculo com a democracia, promovendo uma contextualização introdutória no pensamento freireano. Na sequência, adentramos no que chamamos de tramas da participação, tramas que se constituem em duas dimensões inter-relacionadas e complementares, a prática e a teórica. A primeira é biográfica, na qual analisamos algumas experiências narradas por Freire nas instâncias pessoais (vividas no cotidiano) e profissionais (inseridas nas relações diretamente profissionais), reveladoras de uma apropriação da postura participativa. A segunda enfoca a dimensão teórica, investigando autores e autoras que influenciaram Paulo Freire, bem como a prática da reflexão que sempre adotou na sua postura curiosa em relação à realidade. Nas considerações finais sintetizamos o percurso investigativo, visando elencar os principais achados que a pesquisa possibilitou.

\section{Participação, conceito e base da democracia na obra de Paulo Freire}

A participação pode se referir à ação e ao efeito de participar, podendo implicar na tomada de decisão, dependendo do contexto. Conforme Bobbio, Matteuci e Gianfranco (1998, 888):

\footnotetext{
Na terminologia corrente da ciência política, a expressão Participação política é geralmente usada para designar uma variada série de atividades: o ato do voto, a militância num partido político, a participação em manifestações, a contribuição para uma certa agremiação política, a discussão de acontecimentos políticos. a participação num comício ou numa reunião
} 
de seção, o apoio a um determinado candidato no decorrer da campanha eleitoral, a pressão exercida sobre um dirigente político, a difusão de informações políticas e por ai além.

Nesse sentido é conhecida como participação cidadã, tipicamente prevista nas sociedades democráticas, sobretudo ocidentais. Como a democracia se caracteriza, majoritariamente, como representativa, a participação tende a se resumir ao momento do voto, quando são escolhidos os representantes que ocuparão os cargos no poder executivo e no poder legislativo. Streck e Adams (2006) destacam, juntamente com o voto, as manifestações públicas, os movimentos sociais, as associações, as redes (sociais), os fóruns da sociedade civil, as câmaras setoriais, a gestão participativa, as conferências e os conselhos como outras formas de participar; denominam-nas como lugares da participação. Considerando ambas as definições - ato ou efeito de participar, de maneira genérica, e participação como envolvimento nas decisões políticas, como participação cidadã. problematizamos a participação como construção existencial humana que depende e se origina de processos de aprendizagem.

De acordo com Marshall (1967) a cidadania, a partir da modernidade, subdivide-se em civil, política e social. A primeira diz respeito ao período de sistematização do direito burguês, garantidor das liberdades individuais, conforme demonstra a Declaração dos Direitos do Homem e do Cidadão (1789). 5 A cidadania política é sedimentada ainda no século 19, através da participação em democracias representativas e é o voto que a simboliza, conferindo ao cidadão o papel de agente nas relações de poder. E, por fim, a cidadania social, composta por um conjunto de temas específicos, emergentes a partir da ação de grupos que reivindicam direitos.

Nas palavras do autor (1967, 61):

Os direitos políticos estão relacionados ao direito de participar no exercício do poder político como um membro de um organismo investi-

\begin{abstract}
do da autoridade política ou com eleitor dos membros de tal organismo. Os direitos civis são necessários à liberdade individual, liberdade de ir e vir, liberdade de imprensa, pensamento, fé, o direito à propriedade e de concluir contratos válidos e o direito à justiça. Enquanto que os direitos sociais referem-se a um mínimo de bem-estar econômico e segurança, ao direito de participar por completo da herança social e levar a vida de um ser civilizado de acordo com os padrões que prevalecem na sociedade.
\end{abstract}

O que Marshall explicita é que os modos de produção e de consumo dominantes, ao primar pela posse do capital, determinam a capacidade de participação. Comparativamente, o consumo é o ópio pós-moderno condicionando o comportamento coletivo, responsável pela alienação, e conduzindo ao individualismo sem limites

Contrariando essa perspectiva sistêmica, o pensamento de Paulo Freire considera que a participação resulta de um processo de aprendizagem, pois assim como "é decidindo que se aprende a decidir" (Freire 1996, 119), é participando que se aprende a participar. A educação pode e deve construir a cultura da participação:

Quanto mais as pessoas participarem do processo de sua própria educação, maior será sua participação no processo de definir que tipo de produção produzir, e para que e por que, e maior será também sua participação no seu próprio desenvolvimento. Quanto mais as pessoas se tornarem elas mesmas, melhor será a democracia. Quanto menos perguntarmos às pessoas o que desejam e a respeito de suas expectativas, menor será a democracia (Horton e Freire 2003, 149).

Por essa perspectiva se configura um enfrentamento das relações mercadológicas que tem avançado sobre os processos educativos de maneira geral. Quem define o que e como deve ser estudado? O que importa ser avaliado e como deve ser o processo avaliativo? Tais definições costumam ser tarefa exclusiva de órgãos governamentais os quais, não raro, se submetem à ingerência dos interesses privados. A apropriação ou o oposto, a não apropriação desse processo 
pelos sujeitos concretamente implicados é uma forma de negação da cidadania na perspectiva da participação e da democracia. O protagonismo cognitivo remete a essa origem, não implicando apenas no contexto de sala de aula e nas relações entre professor, aluno e conteúdo. Afinal, nesse momento o processo já chega pré-definido por sujeitos anônimos e direcionado segundo os seus interesses. O que resta a professores e alunos? Apenas o cumprimento de programas fixados pela lógica sistêmica, reproduzindo um ciclo de apassivamento e negação das múltiplas possibilidades de construir conhecimento.

É por isso que cabe à educação constituir-se em vetor de formas mais radicais de participação teórica e prática, almejando um nível mais profundo de percepção dos fatos. A alfabetização, por exemplo, pode assumir duas perspectivas de ação, dependendo da visão de mundo daqueles que a coordenam. Em uma, os analfabetos são indivíduos marginalizados e inferiores, que precisam ser inseridos, incluidos no estilo de vida dominante. Os educadores são agentes de inclusão, imbuídos da tarefa de emancipar os marginalizados de sua condição, excessivamente, inferior - uma espécie de salvação dos excluidos, para que possam participar, minimamente, da dinâmica social que se moderniza a cada dia. Na outra, em que os analfabetos são considerados oprimidos pelo sistema, a educação assume a tarefa humanizadora e libertadora de constituir sujeitos sociais. Suas características, em conexão com a visão de mundo que sustenta, assim a revelam.

Participar implica,

[...] por parte das classes populares, um "estar presente na História e não simplesmente nela estar representadas." Implica a participação politica das classes populares através de suas representações ao nivel das opções, das decisões e não só do fazer o já programado. Por isso é que uma compreensão autoritária da participação a reduz, obviamente, a uma presença concedida das classes populares a certos momentos da administração [...] Participação popular para nós não é um slogan, mas a expressão e, ao mesmo tempo, o caminho de realização democrática da cidade (Freire 2006, 75).

Nos primeiros anos da década de 1960 (século 20), surge no Brasil o Programa Nacional de Alfabetização do Ministério da Educação (MEC), na esteira dos objetivos "inclusores" até então empreendidos. Porém, a alfabetização vem acompanhada de outro termo, a conscientização, de acordo com o inovador método Paulo Freire de alfabetização de adultos. Surge uma outra face da educação popular, com seus novos fundamentos teóricos bem mais afinados com as emergências concretas de um país subdesenvolvido, em busca de crescimento:

Estavam ai apontados os elementos indispensáveis à compreensão das vicissitudes da educação popular, nos primeiros anos da década de 1960. Como pano de fundo, a formação das grandes "massas urbanas" e sua crescente participação na vida política. Como atores principais, os diversos agentes e movimentos empenhados na conquista da influência sobre estas populações. A "emergência das massas urbanas" e, no final do período, também de alguns contingentes das "massas camponesas". a miséria popular no país subdesenvolvido, e as potencialidades revolucionárias inerentes a esta condição, a atuação das lideranças "populistas" e a política "populista" em geral, o nacionalismo, a ação social da Igreja Católica. a atividade política de partidos ou agrupamentos revolucionários, a reação da "ordem" contra as ameaças visualizadas em cada um destes fatores e na ação de conjunto de todos eles, foram sobretudo estes os elementos que permearam a criação e a prática do método de Paulo Freire (Beisiegel 1989, 17).

Com Freire, inverte-se toda uma lógica interna daquela educação popularista. Se antes a dinâmica visava inserir no povo valores que lhe eram externos, nesse momento, o fundamental era assumir com o mesmo os seus valores, para, a partir deles e sem negá-los, qualificá-los diante da sociedade classista. A outra inversão tem lugar nos objetivos ideais do processo educativo, anteriormente, a serviço da acomodação popular e, a partir daí, modificando-se, logrando a desacomodação. De uma ação impositiva, passava-se, pouco a pouco, à ação libertadora. Mesmo direcionado pelo Estado, imbuido de anseios desenvolvimentistas, a interpretação freireana de que se tratava de um processo de mudança, necessário à democratização, revestia o movimento de educação popular de um ideal libertador.

Na sequência almejamos adentrar nas tramas 
da participação elaboradas por Paulo Freire na sistematização de seu pensamento político e pedagógico. Iniciamos analisando aspectos biográficos de sua vida, com ênfase nas experiências que, acredita-se, teriam contribuído para a incorporação dos processos participativos como mediações pedagógicas. A seguir, aprofundaremos a abordagem teórica que teve início com o projeto sobre a arqueologia (considerada como uma escavação profunda na obra) do pensamento de Freire, explorando os referenciais que ele adotou ao longo de seus escritos.

\section{As tramas da participação em Paulo Freire: experiências vividas}

A partir de Freire estamos falando de participação como mediação pedagógica, porém, que participação é essa? Trata-se da participação concebida em um projeto de sociedade, atrelada, portanto, a uma concepção educacional, política e econômica específica. De maneira ampla, uma concepção democrática que almeja instaurar processos de permanente radicalização da participação, assentada em princípios tais como liberdade, responsabilidade, respeito e tolerância.

É a partir do exercício participativo que os integrantes de um grupo podem construir um posicionamento novo, capaz de conduzir a tomada autônoma de decisões. Dessa forma, "toda ação educativa é um processo de descobrimento, criação e recriação de conhecimentos" (Jara 1985, 10), em que conhecer se constitui em imperativo para agir e agir, em imperativo para transformar. A pedagogia freireana se constitui como um processo participativo de construção e apropriação do conhecimento, assim como de tecnologias para transformação da sociedade. Na Pedagogia da esperança, obra permeada de reflexões, Freire $(1992,12)$ explica já na introdução primeiras palavras - que procura "analisar ou falar de tramas da infância, da mocidade, dos começos da maturidade em que a Pedagogia do oprimido", com a qual se reencontra reflexivamente, "era anunciada e foi tomando forma, primeiro, na oralidade, depois, graficamente". Ele mesmo sinaliza para as tramas teórico-práticas a partir das quais gestou seu pensamento, remetendo à infância e demais momentos concretamente vivenciados. Sua narrativa conecta fatos, experiências marcantes com sentimentos de profundo significado existencial. É assim que destaca, por exemplo, a "experiência que pusera fim à recém iniciada carreira de advogado" lembrando da emoção seguida de sua definição radical em diálogo com Elza, sua esposa: "já não serei advogado" (Freire 1992, 16-17). Em seguida afirma não imaginar, naquele momento, que anos depois "escreveria a Pedagogia do oprimido, cujo discurso, cuja proposta tem algo que ver com a experiência daquela tarde" (Freire 1992, 18).

As tramas teórico-práticas, aprofundadas pela reflexão permanente sobre a participação vivenciada ao longo da vida, são explicitadas por Freire (1992) nas seguintes passagens:

Interessante, no contexto da infância e da adolescência, na convivência com a malvadez dos poderosos, com a fragilidade que precisa virar a força dos dominados, que o tempo fundante do SESI, cheio de "soldaduras" e "ligaduras" de velhas e puras "adivinhações" a que meu novo saber emergindo de forma critica deu sentido. eu "li" a razão de ser ou algumas delas, as tramas de livros já escritos e que eu não lera ainda e de livros que ainda seriam escritos e que viriam a iluminar a memória viva que me marcava. Marx, Lukács, Fromm, Gramsci, Fanon, Memmi, Sartre, Kosik, Agnes Heller, M. Ponty, Simone Weill, Arendt, Marcuse [...] (19-20).

Neste esforço de relembrar momentos de minha experiência que, necessariamente, não importa o tempo em que se deram, se constituiram como fontes de minhas reflexões teóricas, ao escrever a Pedagogia do oprimido e continuariam hoje ao repensá-la, me parece oportuno referir-me a um caso exemplar que vivi nos anos 50. Experiência de que resultou um aprendizado de real importância para mim [...] (20).

Referia-se ao periodo em que esteve no Serviço Social da Indústria (SESI), experiência na qual "tramou algo de que a Pedagogia (do oprimido) foi uma espécie de alongamento necessário" $(1992,18)$.

O período de exílio, principalmente o vivenciado no Chile, se constitui como outra fonte de aprendizagens marcantes para Freire. Como ele explica, "os quatro anos e meio que 
vivi no Chile foram assim anos de um profundo aprendizado" (1992, 43). Essas experiências de aprendizagem, tramadas com "o tempo fundante do SESI, se consolidaram na prática chilena e na reflexão teórica que sobre ela fiz" (1992, 44).

São muitas as tramas oriundas de experiências marcantes quanto à participação sobre as quais se salientam, de forma breve e introdutória, alguns exemplos extraídos da Pedagogia da esperança: um reencontro com a pedagogia do oprimido. As experiências ora ilustradas compreendem momentos pessoais e profissionais em profunda conexão, provocando tramas formadoras do sujeito em processo. Constituindo-se em meio às aprendizagens extraídas do vivido, da reflexão sobre o vivido e do diálogo teórico que o complementa e aprofunda, envolvendo um autêntico processo epistemológico crítico. Percebe-se que nessas experiências o fazer parte - participar ativa e intensamente - é uma característica do sujeito, ao mesmo tempo protagonista e narrador. São relembrados processos complexos, repletos de interação, cuja vivência repercutiu de maneira constante na aprendizagem do sujeito, no seu desenvolvimento. O protagonismo revelado nessas experiências fora incorporado pelo sujeito em desenvolvimento, evidenciando, por meio das tramas a partir do vivido-refletido, a participação como protagonismo histórico.

\section{As tramas da participação em Paulo Freire: influências teóricas}

Participação como protagonismo histórico. Em "A imaginação sociológica", Mills (1959) problematiza as condições que permitem a manutenção da ordem social, salientando a apatia das massas como elemento fundamental das sociedades da época. Paulo Freire analisou essa obra de Mills, conforme se observa em seus livros Educação como prática da liberdade (1967). Ação cultural para a liberdade e outros escritos (1981), Pedagogia do oprimido (1987). Educação e mudança (1979) e Pedagogia da autonomia: saberes necessários à prática educativa (1996). Mills (1959) afirma que toda a simbologia socialé organizada para legitimar o modo de ser e as relações de poder tal como elas estão, evitando rupturas. Sobretudo a educação como sistema coordenado, que atua para legitimar o poder instituido. Diante disso, a participação não caberia, menos ainda uma educação para a participação.

Em outra obra, A nova classe média. Mills (1969) analisa o surgimento de uma nova classe média nos Estados Unidos diante das transformações socioeconômicas pós-segunda revolução industrial. Preocupado bem mais com a democracia política do que com a econômica, Mills traça um perfil psicológico que caracteriza uma postura coletiva contrária à democratização do poder, moldada por uma cultura de massas alienante e conservadora em relação às próprias conquistas. Ele considera que a classe média reúne interesses e propósitos específicos em relação, por exemplo, às classes economicamente inferiores, visando manter seu status social e padrão de vida. Consequentemente, a perspectiva política e social dessa classe acaba se alinhando à cultura das elites dominantes e assumindo como seus os mesmos interesses conservadores e autoritários.

A participação popular não se materializa apenas por meio dos mecanismos institucionais e/ou legais, como o voto em período de eleições, o que reflete uma participação institucionalizada. Pensando em termos de radicalidade democrática, ela necessita ir além desses mecanismos, transgredindo o formalmente previsto. Afinal, a participação é um processo social que possibilita às camadas populares manifestar seus anseios, interesses e necessidades, interferir, influenciar, participar da elaboração e da tomada de decisão, bem como controlar sua implementação. Com Freire, tratar da participação popular é tratar. necessariamente, da construção do ser humano enquanto sujeito transformador da história.

A historicidade que Freire considera é reflexo das muitas influências de Marx em seu pensamento. Somente a partir da compreensão da presença do passado na concretude da realidade atual será possivel buscar um protagonismo autêntico. É isso que caracteriza a sua visão possibilista, segundo a qual a realidade está sendo construída, permanentemente, pela ação 
humana. Como Marx $(1971,15)$ Freire acredita que "os homens fazem a sua própria história, mas não a fazem arbitrariamente, nas condições escolhidas por eles, mas antes sob as condições diretamente herdadas e transmitidas pelo passado".

A afirmação do protagonismo histórico de influência marxista, Freire explicita no processo educativo ao explicar que todos, na condição de sujeitos, ensinam e aprendem ao mesmo tempo. Aprender e ensinar são experiências fundamentais e inseparáveis, as quais se consolidam radicalmente ao serem protagonizadas por todos os participantes do processo. E o movimento de libertação, como processo histórico, parte do protagonismo dos oprimidos. Portanto, tomando a ação educativa como referência, é imperativo que se rompam as posturas passivas do espectador. substituindo-as pelo protagonismo do sujeito que atua como ser em construção.

A visão de mundo como processo, aparentemente compartilhada por Freire e Vigotski, compreende uma concepção educativa que transcende a tradicional fragmentação da aprendizagem. Enfatizando o processo, ambos concebem o mundo como realidade objetiva da qual o ser humano é uma parcela orgânica e ativa, constitui-se como historicidade, forma não determinista de compreendê-lo. Por isso, ao invés de separar, a pedagogia freireana busca conectar múltiplas dimensões envolvidas no movimento cognitivo, com ênfase na relação entre teoria e prática, que é datada e situada (historicidade) no contexto vivencial dos sujeitos. Aprender é desenvolver e o desenvolvimento é resultado de um processo complexo, autenticamente vivenciado por cada sujeito no conjunto de suas interações com o meio (físicas e culturais).

Como realidade histórica, o mundo coloca o sujeito na perspectiva do espaço temporal, cujo dinamismo da feitura pode ser analisado no passado, no presente e no futuro. Inserido nessa dinâmica, aceita que a existência humana é devir e sua realização concebe o futuro como problema aberto à capacidade de realização, de todos e cada um. Com Freire e Vigotsk, ao considerar, necessariamente, a presença do(s) outro(s), do qual o sujeito depende para se constituir, o mesmo passa a ser assumido como a união dos componentes biológico e psíquico, um conjunto que atua afirmativamente diante do mundo. O eusujeito se percebe em sua identidade diferente diante dos outros e se objetiva ao interagir: desde uma base teórico-epistemológica idêntica, ainda que um o faça da pedagogia e outro da psicologia, entende-se que Paulo Freire e Lev Vigotski comungam a concepção de ser humano como sujeito ativo e interativo (Alves 2012, 120). A partir de Freire e Vigotski (cuja produção se concentra no começo do século 20), a subjetividade se explica pela sua dimensão interna e externa em permanente processo de construção. relacionado, diretamente, às práticas sociais e aos significados compartilhados. É experiência social que constitui o sujeito, portanto, a ação no mundo e sua consequente transformação são instâncias inerentes ao ser, o sujeito social.

Segundo Rego (2012, 41), para Vigotski "quando o homem modifica o ambiente através de seu próprio comportamento, essa mesma modificação vai influenciar seu comportamento futuro". A afinidade com Freire é nítida e se materializa no significado e nos objetivos da educação que defende: possibilitar ao homem alcançar o teor de sua existência, intervindo no mundo como sujeito e afirmando sua liberdade. Em outras palavras. participar ativamente da própria formação.

Participação como ação relacional-humanizadora. Com Erich Fromm, Freire encontra amparo na análise sobre a unilateralidade da humanização: somente os opressores são humanos, os demais, apenas coisas. Coisas são passivas, não precisam nem devem atuar. A manutenção da condição humana como objeto conduz à frustração, expressão da contrariedade diante da forma de estar no mundo. Lembremos da negação da vocação humana para ser mais, afirmada por Freire. Uma vez negada, essa vocação gera uma frustração, como explica Fromm (1962, 146-147):

É de se presumir que o grau de destrutividade de cada individuo seja proporcional à intensidade com que sua vida foi tolhida. Não quero com isso referir-me às frustrações individuais de tal ou qual desejo instintivo, porém, à 
mutilação de sua vida inteira, ao bloqueio da espontaneidade do crescimento e da expansão das suas capacidades humanas sensuais, emocionais e intelectuais. A vida possui um dinamismo interior próprio, que tende a crescer, a expressar-se, a ser vivido. Assemelhasse-nos que se esta tendência for baldada, a energia voltada para a vida sofrerá um processo de decomposição, transmutando-se em energias voltadas para a destruição

O fato de ter negada a vocação, caracterizando uma vida não vivida segundo Fromm, resulta na frustração, na destrutividade de si mesmo e das outras pessoas. A partir de uma abordagem psicanalítica, Fromm (1962, 148) aponta mecanismos de fuga, entre os quais o mais adotado é a negação de si mesmo, quando o indivíduo "adota inteiramente o tipo de personalidade que the é oferecido pelos padrões culturais", e se torna exatamente o que a sociedade espera que ele seja.

Com Buber, Jaspers e Marcel, Freire irá tramar uma compreensão relacional entre os seres humanos fundada no encontro dialógico autêntico. Encontro apropriado e contextualizado no âmbito das relações opressor-oprimido, no qual o diálogo tem lugar entre os primeiros. Eu e tu (tudo que é outro, pessoas, coisas) representa um encontro do ser com o mundo, ao passo que eu e isso. normalmente atribuido a relações com as coisas, também pode ser encontrado nas relações entre as pessoas. Pessoas coisificadas: "o homem não pode viver sem o ISSO, mas aquele que vive somente com o ISSO não é homem" (Buber 1974, 39). E Buber (1982, 53) ainda distingue três tipos de diálogo: o autêntico, o técnico e o monólogo. O primeiro caracteriza a reciprocidade, cada um tem em mente o outro ou os outros em suas relações. O segundo compreende estritamente as necessidades objetivas e técnicas e o último, disfarçado de diálogo, na verdade consiste em uma fala consigo mesmo.

A partir de Buber e da influência de Karl Jaspers e Gabriel Marcel, Freire consolida uma compreensão existencial do diálogo, considerado a expressão radical da comunicação entre os sujeitos. Com eles, Freire $(1979,68)$ define o diálogo como "uma relação horizontal de A com B", que se nutre "de amor, de humanidade, de esperança, de fé, de confiança". O ser humano dialógico consiste, portanto, em estar aberto ao mundo e aos outros, ratificando a dimensão conectiva do encontro entre sujeitos.

A participação como prática de liberdade. A pedagogia de Freire também opera, como fez Frantz Fanon, um desvelamento da responsabilidade política do oprimido (colonizado). Como Fanon, Freire quer explicitar aos oprimidos que a situação de opressão também depende deles para se manter. A partir da obra de Fanon "Os condenados da terra", publicada originalmente em 1961, assim como da obra de Albert Memmi "O retrato do colonizado precedido pelo retrato do colonizador" de 1966. Freire compreende a dinâmica cruel da introjeção da cultura do opressor que o oprimido sofre. $O$ oprimido é hospedeiro do opressor. Por isso, somente eles, os oprimidos, podem romper com a condição em que se encontram na sociedade.

O sistema de exploração e de submissão fora internalizado no psicológico do sujeito, que dele somente poderá se libertar se compreender e assumir ativamente a luta pela própria liberdade. Trata-se de um processo a ser provocado por dentro, jamais será autêntico se vier de fora do sujeito, como um fazer para. Como Freire salienta em Pedagogia do oprimido (1987. 52), "ninguém liberta ninguém, ninguém se liberta sozinho: os homens se libertam em comunhão". É por isso que a reflexão crítica e os processos de conscientização se tornam inerentes à libertação.

Desde os seus primeiros escritos, como Educação e atualidade brasileira. Freire formula uma análise crítica da sociedade brasileira apoiando-se em referenciais como Álvaro Vieira Pinto (ideologia do desenvolvimento atrelada à educação do povo), Fernando de Azevedo e Gilberto Freyre (a herança colonial e a cultura da submissão consolidada com o apoio da educação jesuítica, verbalista). Dessa compreensão crítica inicial, tal como uma denúncia, Freire parte para a proposição de caminhos anunciadores de uma outra perspectiva nacional que fosse embasada na abertura democrática, construindo-se em processos de educação para a participação das massas. 
Na perspectiva do anúncio, percebe-se a presença de Karl Mannhein e Zevedei Barbu em meio à afirmação necessária de experiências dialógicas e não autoritárias, as únicas capazes de inaugurar uma democracia com o povo. Freire já pensava a participação como uma experiência dialógica desde o interior das instituições públicas, principalmente. Ele demonstra desde Educação e atualidade brasileira, escrito em 1959, uma concepção sobre a democracia e a participação como, necessariamente, resultantes de processos educativos, cuja aprendizagem se dá pela experiência concreta: "se há um saber que só se incorpora ao homem experimentalmente. existencialmente, este é o saber democrático" (Freire 2002, 15).

Freire entende que, por exemplo, uma instituição educacional, seja escola ou universidade, que reproduzir tão somente os mesmos princípios da democracia representativa não estará promovendo nenhum tipo de ruptura com o instituido. Por esses principios, um número muito maior de pessoas não atua efetivamente de maneira participativa, pois abdica dessa atuação em nome de um pequeno grupo de representantes. Como será possível formar uma cultura participativa se não exercitar a participação? Quais são os pressupostos formativos da participação, ou seja, o que é possivel e necessário para que uma pedagogia se caracterize como formadora de sujeitos participantes politicamente? Todas essas questões remetem às mediações pedagógicas e às experiências participativas na forma de processos de aprendizagem.

\section{Considerações finais}

No processo investigativo percebeu-se que a participação é assumida como condição fundante do processo de humanização no contexto social, por meio da qual os sujeitos se constroem politicamente. Ao mesmo tempo, participar é condição pedagógica dessa construção, pois sem o seu exercício concreto não é viabilizada a aprendizagem e a incorporação do conhecimento pelo sujeito. A partir dessa pesquisa, evidenciou- se a existência de uma relação conectiva, orgânica e complementar entre processos participativos e processos de aprendizagem. Constatou-se também que essa relação constitui uma lógica fundante do pensamento pedagógico e político de Paulo Freire. Sua estrutura mestra é a articulação entre prática, envolvendo experiências pessoais e profissionais, e teoria, tanto aquela resultante do estudo e da influência de autores e autoras como a construída por meio do movimento de sua prática de pensar a própria prática (reflexão).

Na dimensão biográfica, foram evidenciadas e analisadas experiências impactantes para que Freire tenha afirmado a participação ao longo de toda a sua história de vida. Na dimensão teórica, percebeu-se que as tramas que Paulo Freire constrói em torno da participação conectam, de maneira complexa, múltiplas referências. A arqueologia bibliográfica havia revelado a incorporação construtiva e articulada de teóricos oriundos de áreas como sociologia, linguística, filosofia, pedagogia, física, entre outras. Desenvolvendo um trabalho transdisciplinar do ponto de vista intelectual, Freire agrega na formulação de seu pensamento distintas concepções teóricas. E o faz tramando os múltiplos fios que foi selecionando no processo de construção teórica da sua pedagogia do oprimido.

Dessas tramas entre influências teóricas e experiências vivenciais, Freire foi capaz de elaborar uma concepção pedagógica que afirma a educação como ação diretiva e, ao mesmo tempo, projetiva. É direcionada, pois, como parte de um projeto que acredita e exige que os sujeitos possam ir além daquilo que são no momento. É por isso que a neutralidade da prática educativa é impossivel: como projeto, educar envolve objeto (conteúdos) e objetivos (metas). E os sujeitos que projetam (educadores), ao fazê-lo, necessitam decidir, romper e optar, tarefas típicas, conforme Freire $(2001,69)$ de sujeitos participantes.

A participação como componente existencial, apropriada pelos sujeitos, tende a tencionar e extrapolar os limites do instituido, buscando ampliar suas ações e espaços de influência. Com isso, é possivel considerar, por exemplo. 
que as apropriações estratégicas da participação planejadas pela esfera governamental enfrentarão resistência. Não raro a participação, assim como a defesa da democracia, na sua dimensão discursiva é assumida como slogan. espécie de artifício para legitimar determinados projetos políticos. Projetos que, na perspectiva da participação como princípio, deveriam ser construidos de maneira participativa desde a sua gênese. Paulo Freire teria compreendido com bastante clareza tais riscos; por isso, estruturou seu pensamento político e pedagógico sobre os pilares da participação em processo de radicalização permanente. Sem superar a dimensão instrumental, bastante comum no meio partidário/governamental, a participação continua manipulada, ao mesmo tempo em que as práticas conservadoras e autoritárias de gestão pública se reproduzem e perpetuam.

\section{Referências}

Alves, Solange Maria. 2012. Freire e Vigotski: um diálogo entre a pedagogia freireana e a psicologia histórico-cultural. Chapecó: Argos. https://doi.org/10.11606/t.48.2008. tde-16062008-133010.

Beisiegel, C. R. 1989. Política e educação popular: a teoria e a prática de Paulo Freire no Brasil. São Paulo: Ática.

Bobbio, Norberto, Nicola Matteucci e Gianfranco Pasquino. 1998. Dicionário de Política. Brasília: Editora UnB.

Buber, Martin. 1974. Eu e tu. São Paulo: Moraes.

Buber, Martin. 1982. Do diálogo e do dialógico. São Paulo: Editora Perspectiva.

Freire, Paulo. 2002. Educação e atualidade brasileira. 2. ed. São Paulo: Cortez.

Freire, Paulo. 1979. Educação e mudança. Rio de Janeiro: Paz e Terra.

Freire, Paulo. 1967. Educação como prática da liberdade. Rio de Janeiro: Paz e Terra.

Freire, Paulo. 1981. Ação cultural para a liberdade e outros escritos. Rio de Janeiro: Paz e Terra.

Freire, Paulo. 1987. Pedagogia do oprimido. Rio de Janeiro: Paz e Terra.

Freire, Paulo. 1996. Pedagogia da autonomia: saberes necessários à prática educativa. São Paulo: Paz e Terra. https://doi.org/10.18764/2446-6549.2019.10355.

Freire, Paulo. 2001. Politica e educação. São Paulo: Cortez.
Freire, Paulo. 1992. Pedagogia da esperança: um reencontro com a pedagogia do oprimido. Rio de Janeiro: Paz e Terra. https://doi.org/10.22294/eduper/ppge/ ufv.vgi3.1108.

Freire, Paulo. 2006. A educação na cidade. São Paulo: Cortez.

Fromm, Erich. 1962. O medo à liberdade. Traduzido por Octavio Alves Velho. Rio de Janeiro: Zahar Editores.

Horton, Myles e Paulo Freire. 2003. O caminho se faz caminhando: conversas sobre educação e mudança social. Petrópolis: Editora Vozes.

Jara, Oscar. 1985. Concepção dialética da educação popular. São Paulo: Cepis.

Marx, Karl. 1971. O 18 do Brumário de Louis Bonaparte. Traduzido por Maria Teresa de Sousa. Coimbra: Editora Nosso Tempo.

Marshall, Thomas H. 1967. Cidadania, classe social e status. Rio de Janeiro: Zahar.

Mills, Charles Wright. 1959. A imaginação sociológica. Rio de Janeiro: Zahar.

Mills, Charles Wright. 1969. A nova classe média. Rio de Janeiro: Zahar.

Rego, Teresa Cristina. 2012. Vygotsky: uma perspectiva histórico-cultural da educação. 23 ed. Petrópolis, RJ: Vozes.

Streck, Danilo Romeu e Telmo Adams. 2006. Lugares da participação e formação da cidadania. Civitas: revista de Ciências Sociais 6, n 1: 95-117. https://doi. org/10.15448/1984-7289.2006.1.24.

\section{Sandro de Castro Pitano}

Doutor em Educação pela Universidade Federal do Rio Grande do Sul (Ufrgs, Porto Alegre, RS, Brasil). Professor do Programa de Pós-Graduação em Educação da Universidade de Caxias do Sul (UCS) em Caxias do Sul, RS, Brasil.

\section{Danilo Romeu Streck}

Doutor em Educação pela Rutgers University (New Jersey/US). Professor do Programa de Pós-Graduação em Educação da Universidade do Vale do Rio dos Sinos (Unisinos) em São Leopoldo, RS, Brasil.

\section{Cheron Zanini Moretti}

Doutora em Educação pela Universidade do Vale do Rio dos Sinos (Unisinos, São Leopoldo, RS, Brasil). Professora do Programa de Pós-Graduação em Educação da Universidade de Santa Cruz do Sul (Unisc) em Santa Cruz do Sul, RS, Brasil. 